\title{
Life course social mobility and risk of upper aerodigestive tract cancer in men
}

\author{
N. Schmeisser - D. I. Conway • P. A. McKinney - A. D. McMahon • \\ H. Pohlabeln · M. Marron · S. Benhamou • C. Bouchardy · G. J. Macfarlane • \\ T. V. Macfarlane - P. Lagiou - A. Lagiou - V. Bencko - I. Holcátová • \\ F. Merletti - L. Richiardi - K. Kjaerheim • A. Agudo - R. Talamini \\ J. Polesel - C. Canova $\cdot$ L. Simonato $\cdot$ R. Lowry $\cdot$ A. Znaor $\cdot$ C. Healy $\cdot$ \\ B. E. McCarten · M. Hashibe · P. Brennan - W. Ahrens
}

Received: 4 September 2009/Accepted: 20 January 2010/Published online: 9 February 2010

(C) Springer Science+Business Media B.V. 2010

\begin{abstract}
The aim of this study was to explore associations between social mobility and tumours of the upper aero-digestive tract (UADT), focussing on life-course transitions in social prestige (SP) based on occupational history. 1,796 cases diagnosed between 1993 and 2005 in ten European countries were compared with 1585 controls. SP was classified by the Standard International Occupational Prestige Scale (SIOPS) based on job histories. SIOPS was categorised in high $(H)$, medium $(M)$ and low $(L)$. Time weighted average achieved and transitions between SP with nine trajectories: $H \rightarrow H, H \rightarrow M, H \rightarrow L$,
\end{abstract}

\author{
N. Schmeisser $(\bowtie) \cdot$ H. Pohlabeln · W. Ahrens \\ Bremen Institute for Prevention Research and Social Medicine \\ (BIPS), Linzer Str. 10, 28359 Bremen, Germany \\ e-mail: Nils.Schmeisser@bips.uni-bremen.de \\ D. I. Conway · A. D. McMahon \\ Faculty of Medicine, Dental School, University of Glasgow, \\ Glasgow, UK \\ D. I. Conway · P. A. McKinney \\ NHS NSS ISD, Edinburgh, UK \\ P. A. McKinney \\ Centre for Epidemiology and Biostatistics, University of Leeds, \\ Leeds, UK \\ M. Marron · M. Hashibe · P. Brennan \\ International Agency for Research on Cancer, Lyon, France \\ S. Benhamou \\ INSERM, U946, Fondation Jean Dausset-CEPH, Paris, France \\ S. Benhamou \\ CNRS FRE2939, Gustave-Roussy Institute, Villejuif, France \\ C. Bouchardy \\ Geneva Cancer Registry, Geneva, Switzerland
}

$M \rightarrow H, M \rightarrow M, M \rightarrow L, L \rightarrow H, L \rightarrow M$ and $L \rightarrow L$ were analysed. Odds ratios (ORs) and 95\%-confidence intervals [95\%-CIs] were estimated with logistic regression models including age, consumption of fruits/vegetables, study centre, smoking and alcohol consumption. The adjusted OR for the lowest versus the highest of three categories (time weighted average of SP) was 1.28 [1.041.56]. The distance of SP widened between cases and controls during working life. The downward trajectory $H \rightarrow L$ gave an OR of $1.71[0.75-3.87]$ as compared to $H \rightarrow H$. Subjects with $M \rightarrow M$ and $L \rightarrow L$ trajectories
G. J. Macfarlane - T. V. Macfarlane University of Aberdeen, Aberdeen, UK

P. Lagiou · A. Lagiou

Department of Hygiene, Epidemiology and Medical Statistics, University of Athens Medical School, Athens, Greece

\author{
A. Lagiou \\ Faculty of Health Professions, Athens Technological \\ Educational Institute, Athens, Greece \\ V. Bencko · I. Holcátová \\ 1st Faculty of Medicine, Institute of Hygiene \& Epidemiology, \\ Charles University Prague, Prague, Czech Republic \\ F. Merletti · L. Richiardi \\ Unit of Cancer Epidemiology, CeRMS and University of Turin, \\ Turin, Italy \\ K. Kjaerheim \\ Cancer Registry of Norway, Oslo, Norway
}

A. Agudo

Institut Catala d'Oncologiea, Barcelona, Spain 
ORs were also elevated relative to subjects with $H \rightarrow H$ trajectories. The association between SP and UADT is not fully explained by confounding factors. Downward social trajectory during the life course may be an independent risk factor for UADT cancers.

Keywords Laryngeal cancer - Pharyngeal cancer . Oral cavity cancer - Oesophageal cancer .

Case-control study · Socioeconomic status .

Occupational history

\section{Introduction}

Tumours of the oral cavity, larynx, oropharynx, hypopharynx and oesophagus are designated as upper aerodigestive tract tumours (UADT). Approximately 100,000 men are diagnosed with UADT per year in the European Union [1, 2]. The multifactorial origin of these tumours is well-known. The most important risk factors are consumption of alcohol and tobacco, and the combined exposure leads to a multiplicative risk for these tumour sites [3]. High intake of fruit and vegetables has a protective effect [4-6].

Some epidemiological studies show that employment in several industries with occupational exposures to asbestos, acid mists or solvents are associated with an increased risk of UADT [7]. Occupational characteristics may not only have an effect on cancer outcome via exposures but also by influencing opportunities for social and economic participation and affecting circumstances. In addition, occupation may be a basic variable for lifestyle and psychosocial determinants of health related behaviour [8-10].

Associations between socioeconomic status (SES) and UADT have been observed in several studies, and low SES

R. Talamini $\cdot$ J. Polesel

Unit of Epidemiology and Biostatistics, Centro di Riferimento

Oncologico-IRCCS, Aviano, Italy

C. Canova

Department of Environmental Medicine and Public Health,

University of Padova, Padua, Italy

L. Simonato $\cdot$ R. Lowry

University of Newcastle Dental School, Newcastle, UK

A. Znaor

Croatian National Cancer Registry, Zagreb, Croatia

C. Healy · B. E. McCarten

Trinity College School of Dental Science, Dublin, Ireland

B. E. McCarten

Department of Dental Anatomy, Royal College of Surgeons in Ireland, Dublin, Ireland has been linked to an increased risk of different sites of UADT, independent from other risk factors for this cancer [11-16].

Social status is usually measured by education, income or occupation. An additional dimension is the degree of desirability of a given occupation, which is an expression of its social prestige (SP). The Standard International Occupational Prestige Scale (SIOPS) [17] assigns occupational roles to an occupational prestige hierarchy expressed in scores. The SIOPS is based on a large set of data from studies in 59 countries. It showed to be invariant over time and comparable between countries [17, 18]. The ranks of the SIOPS range from 78 points for physicians and some other occupations with higher education like university teachers to 14 points for unskilled workers in the agricultural sector. How social hierarchy affects health outcome is not fully understood. Modifiable lifestyle factors may explain the effect $[19,20]$.

The aim of this study was to explore associations between social mobility and UADT, focussing on lifecourse transitions in SP and to asses the role of known risk factors of UADT on this association. This analysis is restricted to men because occupational biographies of women tend to be affected by economically inactive periods [21].

\section{Population and methods}

In accordance with the requirements of the local Institutional Review Boards in 14 centres of 10 European countries (Czech Republic, Germany, Greece, Italy, Ireland, Norway, United Kingdom, Spain, Croatia and France) incident cases of UADT were contacted personally through weekly monitoring of the included hospitals. Cases included in this study had a histology confirmed diagnosis of different entities of UADT (Oral cavity (ICD-10: C00.3C09.9; C14.0-C14.9), Larynx (ICD-10: C32.0-C32.9), Oropharynx (ICD-10: C10.0-C10.9), Hypopharynx (ICD10: C12.0-C13.9) and Oesophagus (ICD-10: C15.0C15.9).

In each center, controls were frequency-matched to cases by age (5-year groups) and sex. In the UK centres, population controls were randomly selected from the same community medical practice list as the corresponding cases. Specifically, for each case, a total of 10 controls were selected, matched by age and sex. Potential controls were approached in random order one at a time until one agreed to participate [22]. In all other centres hospital admitted controls for a wide spectrum of medical conditions were ascertained [23]. None of these patients had malignant tumours or diseases associated with alcohol consumption or smoking. In the hospital based centres 
subjects from rural or remote areas were included, but this variable was not provided for analysis.

A structured questionnaire was used and blood samples were taken to analyse risk factors and genetic susceptibility on cancer outcome in UADT. Data were pooled, controlled and managed at the International Agency for Research on Cancer (IARC), Lyon.

A standardized questionnaire was applied by a face-toface interview to cases and controls to obtain information on demographic details, physical constitution and occupational history. Past and present smoking and alcohol consumption, diet, and medical factors were assessed in detail.

A detailed occupational history was recorded by year of beginning and end, job title and branch of industry for each occupational period held at least 3 years on the basis of performed tasks and industry. In every centre job descriptions and titles were coded blindly to case/control status in respect to the International Standard Classification of Occupations [ISCO] version from 1968 [24].

The recruitment period of controls and incident cases for the French study took place between 1987 and 1992 and for all other participating centres between 2002 and 2005. A casecontrol ratio of at least 1:1 was aspired. All included subjects were Caucasian. Detailed information about the study population and the study design is described elsewhere [23].

\section{Assessment of social prestige}

All occupational biographies were checked for plausibility (e.g. correct order of starting and ending years of jobs, duration of education and work biographies). Incomplete job histories were discarded from the analysis dataset. The study sample comprised 1,796 cases and 1,585 controls after exclusion of 55 cases and 76 controls due to incomplete job biographies or other explaining variables.

To compare different job titles from different countries the ISCO was utilized. ISCO-codes were connected with SIOPS-values using a matrix for each job period. After restriction to the first three ISCO digits 267 different job titles were derived. SP was grouped in three categories each spanning over an equal number of occupations.

For periods with two parallel jobs the maximum value of SP of both jobs was taken. Occupations in a family context, honorary working and subsistent farming were excluded. The duration of a job period was calculated by subtracting year of start from year of end plus 0.5.

SP was analysed at different time points: SP value of first job or value for job held at age of at least 18, last occupation, maximum and time-weighted average mean of all occupations. Time weighted average of SP was defined as the sum of the products of SP of the jobs held and the duration of this job divided through the total time employed. SP was categorised in tertiles $(H=$ high, $M=$ medium, $H=$ high) with the highest category as reference. The maximum SIOPS score was assessed for each 10-year age interval between the age of 21 and 60. For the age groups 20 years and below as well as 60 years and older analyses were done without age constraint.

Transitions were analysed by grouping SIOPS values into three classes based on the three categories as mentioned above. Transitions between these categories were analysed for first job to last job and first job to job with maximum SIOPS value. Nine socioeconomic trajectories were analysed: (1) $H \rightarrow H$, (2) $H \rightarrow M$, (3) $H \rightarrow L$, (4) $M \rightarrow H$, (5) $M \rightarrow M$, (6) $M \rightarrow L$, (7) $L \rightarrow H$, (8) $L \rightarrow M$, and (9) $L \rightarrow L$.

\section{Statistical analysis}

Odds ratios (ORs) and corresponding 95\% confidence intervals (95\%-CIs) were calculated with logistic regression models which included the following variables: age (9 categories: <40, 40-44, 45-49, 50-54, 55-59, 60-64, 65-69, $70-74,75+$ years) dummy variables for each study centre, smoking status (never, former and current smoking) and alcohol intake (never, former and current drinking). Lifetime tobacco consumption was classified in 5 categories $(0,>0$ $<20,20-<40,40-<60$ and $60+$ pack-years $)$. Alcohol intake was classified in 5 categories of drinks per day $(<1,1-2,3-4$, $5+$, unknown). The total consumption per week was summed up for all fruit and vegetable variables to get a total fruit or vegetable consumption/week variable. Frequency of fruit and vegetable consumption was categorised by country specific tertiles as low, medium and high [25]. The highest level of SP was chosen as the reference category.

ORs were estimated by unconditional logistic regression analysis, using the PROC LOGISTIC function of the SAS software package, Version 8.2. The logistic regression model 1 included age and study centre $\left(\mathrm{OR}_{1}\right)$. The logistic regression model 2 included variables smoking status (never, former, current) and cumulative consumption of tobacco, alcohol status (never, former, current) and daily alcohol intake, 2 variables for fruit and vegetable intake frequency in addition to variables in model $1\left(\mathrm{OR}_{2}\right)$. Differences between cases and controls in categorical variables were tested by a $\chi^{2}$-statistic. Analyses were also done by stratification for site of UADT (oesophagus, hypopharynx and larynx, oral cavity and oropharynx).

\section{Results}

The size of the study population and the ratio of cases to controls varied between countries. The mean age differed 
only marginally between cases and controls. Cases of UADT were born between 1901 and 1985, controls between 1902 and 1983. Mean age and standard deviation at time of interview for cases was $59.2 \pm 9.6$ (median: 59), for controls $59.3 \pm 10.7$ (median: 59) years (Table 1). More than $80 \%$ of tumour cases were diagnosed with tumours of the larynx and hypopharynx $(N=785 ; 43.7 \%)$ or oral cavity and oropharynx $(N=760 ; 42.3 \%)$. Tumours of the oesophagus $(N=169 ; 9.4 \%)$ were less frequent. For 82 cases $(4.6 \%)$ it was not possible to assess the site of origin within the UADT (data not shown).

Consumption of tobacco and alcohol ever was more frequent in cases than in controls. About $50 \%$ of cases had accumulated 40 pack-years or more or drunk at least three drinks a day, as compared to $20 \%$ of controls. Almost half of the cases were classified as low fruit or vegetables consumers (data not shown).

\section{Occupational characteristics}

The number of economically active periods including military services varied between 1 and 12 job periods for cases and 1 and 13 job periods for controls. $90 \%$ of cases and controls had less than 6 job periods with a median of 2 for cases and 3 for controls (mean values for cases $=2.8$; controls $=2.9$ ). The mean values for duration of work at time of interview were 35.2 years for cases and 35.6 years for controls, excluding economically inactive periods (unemployment, imprisonment, house husband, disease).

\section{Social prestige of occupations}

Risk estimates of the time-weighted average of SIOPS for the all UADT and for the different subsites are presented in Table 2. Similar associations were observed for the SP of the job held longest, the maximum SP during working life and the SP of the last occupation, while for the SP of the first job held no association was observed (not shown).

Over the life course cases showed a lower SP than controls while the distance of SP values between cases and controls increased regardless of the level at which they started their careers (Fig. 1a-c). The mean SP value for all occupations for cases was 36 and 39 for controls. The median value of SP was two points and one point lower than the mean in cases and controls, respectively. In general, upward trends were seen among controls, regardless of the starting level, while cases decreased when starting from the high category and seemed to have no upward trend when starting in category M. Cases starting in the L category showed a slower rise of SP than controls in this category.

Cases had more downward than upward transitions in their career than controls $(P<0.0005)$. While $22.5 \%$ of the cases moved downward $19.8 \%$ of controls had this trend. Vice versa, upward transitions were more frequent in controls $(32.2 \%)$ than in cases $(26.0 \%)$. In 478 cases (26.6\%) and 413 controls $(26.1 \%)$ up- and downward mobility was balanced.

Table 3 displays the risk estimates in relation to transitions of SP. The highest risks were observed for the change $H \rightarrow L$ from the first occupation to the occupation

Table 1 Age distribution of study population in accordance to study centre and case control status

\begin{tabular}{|c|c|c|c|c|c|c|c|}
\hline \multirow[t]{3}{*}{ Country (centre) } & \multicolumn{7}{|c|}{ Analysed study population } \\
\hline & \multicolumn{3}{|l|}{ Cases } & \multicolumn{3}{|c|}{ Controls } & \multirow[t]{2}{*}{$\mathrm{Ca} / \mathrm{Co}$-ratio } \\
\hline & $N$ & $\%$ & Age mean (range) & $N$ & $\%$ & Age mean (range) & \\
\hline Czech. Republic (Prague) & 158 & 8.8 & $57.5(35-76)$ & 148 & 9.3 & $59.5(37-78)$ & 1.07 \\
\hline Germany (Bremen) & 225 & 12.5 & $58.2(42-77)$ & 255 & 16.1 & $58.4(37-81)$ & 0.88 \\
\hline Greece (Athens) & 192 & 10.7 & $61.2(18-82)$ & 136 & 8.6 & $62.0(29-96)$ & 1.41 \\
\hline Italy (Aviano) & 120 & 6.7 & $61.0(40-71)$ & 118 & 7.4 & $60.9(41-80)$ & 1.02 \\
\hline Italy (Padova) & 108 & 6.0 & $61.4(40-78)$ & 93 & 5.9 & $60.8(26-79)$ & 1.16 \\
\hline Italy (Turin) & 115 & 6.4 & $60.7(28-78)$ & 141 & 8.9 & $59.2(32-79)$ & 0.82 \\
\hline Ireland (Dublin) & 29 & 1.6 & $59.4(43-85)$ & 5 & 0.3 & $51.4(25-68)$ & 5.80 \\
\hline Norway (Oslo) & 119 & 6.6 & $60.6(37-80)$ & 106 & 6.7 & $59.6(26-80)$ & 1.12 \\
\hline UK (Glasgow) & 59 & 3.3 & $58.8(41-79)$ & 44 & 2.8 & $62.8(45-81)$ & 1.34 \\
\hline UK (Manchester) & 104 & 5.8 & $58.7(34-80)$ & 116 & 7.3 & $59.7(36-78)$ & 0.90 \\
\hline UK (Newcastle) & 71 & 4.0 & $61.4(40-80)$ & 87 & 5.5 & $61.4(41-90)$ & 0.82 \\
\hline Spain (Barcelona) & 163 & 9.1 & $59.4(36-95)$ & 95 & 6.0 & $61.2(20-96)$ & 1.72 \\
\hline Croatia (Zagreb) & 45 & 2.5 & $54.9(32-72)$ & 36 & 2.3 & $59.0(34-83)$ & 1.25 \\
\hline INSERM (France) & 288 & 16.0 & $55.3(22-89)$ & 205 & 12.9 & $54.1(25-88)$ & $\begin{array}{l}1.40 \\
1.13\end{array}$ \\
\hline Total & 1,796 & & $58.9(18-95)$ & 1,585 & & $59.3(20-96)$ & \\
\hline
\end{tabular}


Table 2 Distribution of cases and controls for achieved time weighted SIOPS values for whole study population and for entities of UADT

\begin{tabular}{|c|c|c|c|c|c|c|}
\hline \multirow[t]{2}{*}{ SP category* } & \multicolumn{2}{|c|}{ Cases } & \multicolumn{2}{|c|}{ Controls } & \multirow[t]{2}{*}{$\mathrm{OR}_{1}[95 \%-\mathrm{CI}]$} & \multirow[t]{2}{*}{$\mathrm{OR}_{2}[95 \%-\mathrm{CI}]$} \\
\hline & $N$ & $\%$ & $N$ & $\%$ & & \\
\hline \multicolumn{7}{|c|}{ Time weighted average complete study ${ }^{b}$} \\
\hline$H$ & 345 & 19.21 & 474 & 29.91 & $1^{\mathrm{a}}$ & $1^{\mathrm{a}}$ \\
\hline$M$ & 730 & 40.65 & 652 & 41.14 & $1.50[1.25-1.78]$ & $1.08[0.88-1.31]$ \\
\hline$L$ & 721 & 40.14 & 459 & 28.96 & $2.04[1.70-2.45]$ & $1.28[1.04-1.56]$ \\
\hline \multicolumn{7}{|c|}{ Oral cavity and oropharyn $x^{b}$} \\
\hline$H$ & 151 & 38.55 & 474 & 29.91 & $1^{\mathrm{a}}$ & $1^{\mathrm{a}}$ \\
\hline$M$ & 316 & 41.58 & 652 & 41.14 & $1.43[1.14-1.80]$ & $1.04[0.81-1.33]$ \\
\hline$L$ & 293 & 19.87 & 459 & 28.96 & $1.81[1.43-2.30]$ & $1.15[0.89-1.50]$ \\
\hline \multicolumn{7}{|c|}{ Hypopharynx and laryn $x^{b}$} \\
\hline$H$ & 146 & 40.51 & 474 & 29.91 & $1^{\mathrm{a}}$ & $1^{\mathrm{a}}$ \\
\hline$M$ & 321 & 40.89 & 652 & 41.14 & 1.57 [1.25-1.98] & $1.10[0.85-1.43]$ \\
\hline$L$ & 318 & 18.60 & 459 & 28.96 & $2.13[1.69-2.70]$ & $1.24[0.95-1.62]$ \\
\hline \multicolumn{7}{|l|}{ Oesophagus $^{\text {b }}$} \\
\hline$H$ & 31 & 18.34 & 474 & 29.91 & $1^{\mathrm{a}}$ & $1^{\mathrm{a}}$ \\
\hline$M$ & 60 & 35.50 & 652 & 41.14 & $1.56[0.98-2.48]$ & 1.24 [0.77-1.99] \\
\hline$L$ & 78 & 46.15 & 459 & 28.96 & 2.84 [1.81-4.47] & $2.02[1.26-3.23]$ \\
\hline
\end{tabular}

${ }^{a}$ Reference. $\mathrm{OR}_{1}$, adjusted for age and study centre; $\mathrm{OR}_{2}$, adjusted for age, study centre; smoking status, cumulative tobacco consumption, alcohol drinking status, alcohol drinking frequency, fruit and vegetable intake frequency

${ }^{\mathrm{b}}$ Cochran-Armitage Trend Test $<0.001$

*Categories chosen for an equal frequency of occupations within scaling points. Number of occupations of the social prestige categories $L=14-33$, $M=34-45$ and $H=46-78$ were 87,88 and 91

with the maximum SP thereafter $\left(\mathrm{OR}_{2} 1.71\right.$ [95\%-CI: 0.753.87]) while no risk elevations were observed for the downward transition $M \rightarrow L\left(\mathrm{OR}_{2}=1.08\right.$ [95\%-CI: 0.751.54]) and only a modest elevation was seen for $L \rightarrow L$ $\left(\mathrm{OR}_{2}=1.24\right.$ [95\%-CI: 0.95-1.61]) (reference $H \rightarrow H$ ).

The transition $H \rightarrow L$ (first to last occupation) resulted in an $\mathrm{OR}_{2}$ of 1.58 [95\%-CI: $0.85-2.94$ ] while the corresponding transition $H \rightarrow M$ resulted in an $\mathrm{OR}_{2}$ of 1.51 [95\%-CI: 0.842.72]. An elevated risk was observed in all men who descended from a higher to a lower class. The risks were similar for $M \rightarrow L\left(\mathrm{OR}_{2}=1.28\right.$ [95\%-CI: 0.95-1.73]) and $M \rightarrow M$ $\left(\mathrm{OR}_{2}=1.33\right.$ [95\%-CI: 1.02-1.73]) and slightly weaker for $L \rightarrow L\left(\mathrm{OR}_{2}=1.24\right.$ [95\%-CI: 0.96-1.62]).

The risk was elevated for at least $21 \%$ for class stability in all these analyses. Furthermore, upward transitions were associated with no or a reduction in risk of UADT.

The maximum difference in SP observed in occupational biographies of study subjects varied between +51 and -41 points. Increased risk estimates were also found in subjects who never changed their job, regardless of whether the first occupation was classified as $H, M$, or $L$ (data not shown).

\section{Risk development at different points of age}

Figure 2 shows that the difference of mean SP values between cases and controls increased continuously with increasing age. For class $M$ and $L$ cases and controls showed a continuous increase of SP until the age of 50 . While the SP values continue to rise until the age of 60 in controls, it remains more or less stable in cases and drops down after the age of 60 . Table 4 displays the corresponding risk estimates relative to the highest SP category by 10 year age groups which reflect these curves, especially for $\mathrm{OR}_{1}$. Further adjustment reduces the risk estimates substantially but the elevated risk remains, predominantly in the older age groups.

\section{Discussion}

These analyses of 1,796 cases and 1,585 controls aimed to identify the effect of occupational prestige differences on the risk of developing UADT. A negative relationship between occupational prestige and downward trajectories of SP during lifetime and the risk of UADT was seen. This corroborates findings by Menvielle and co-workers who found an increased risk for UADT cancers for transitions from white collar jobs to blue collar jobs [15]. However, in contrast to this study, these results were not adjusted for main risk factors. The adjustment for alcohol and tobacco consumption attenuated the effect of SP on the risk of UADT tumours substantially. Further adjustment for frequency of fruit and vegetable intake had only a small 

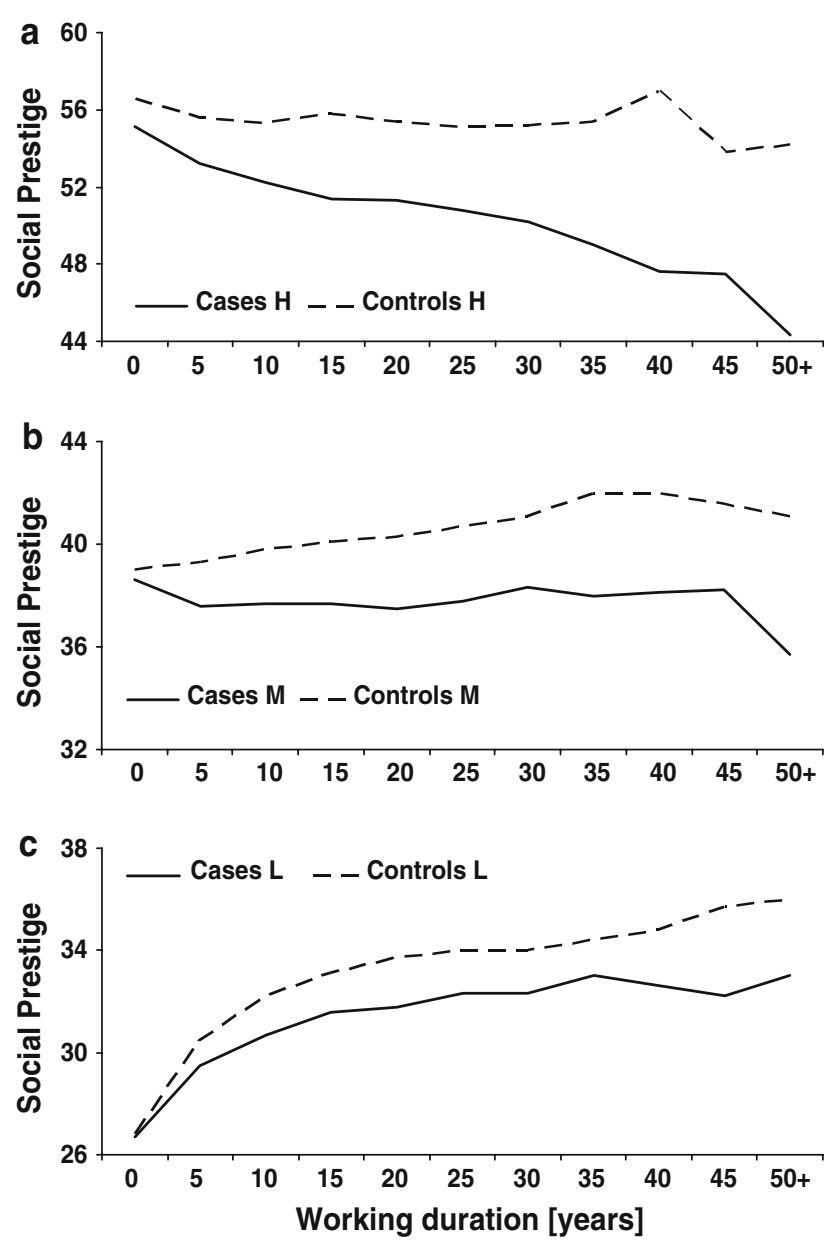

Fig. 1 a-c Development of mean value of social prestige for cases and controls following their occupational biography, grouped in respect of their first occupational prestige into high $(H, \mathbf{a})$, medium $(M, \mathbf{b})$ and low $(L, \mathbf{c})$. Only cases and controls which were economically active were considered. Number of cases declined continuously in respect of age and economically inactive periods from 1,796 to 189 , number of controls from 1,585 to 220 subjects. Number of cases starting in category $H, M$, and $L$ were 266, 791 and 739, number of controls 304, 695 and 586

attenuating effect. Nevertheless, after controlling for alcohol/tobacco consumption and for the frequency of fruit and vegetable intake a relevant effect of SP persisted.

Residual confounding in aspects of alcohol and tobacco consumption should be a minor problem in this study. Every change in tobacco and alcohol consumption pattern was an integral part of the interview. The questionnaire used in the INSERM study differed from all other questionnaires of the pooled study with respect to fruit and vegetable items. A sensitivity analysis excluding the INSERM data did not alter the risk estimates.

In this study hospital controls with diseases related to smoking and alcohol consumption were excluded. Alcohol and tobacco consumption of controls in this study were comparable to those in other case control studies $[5,14$,
26-29]. Since interviewers were not always blinded to the case-control status of a study subject, an information bias can not be ruled out, especially regarding behaviours that are socially desirable like non-smoking and low alcohol consumption. In the case of an underreporting of smoking by cases this might lead to an overestimation of the effect of SP on the risk of UADT tumours even after adjustment. On the other hand, hospital based case-control studies considering education, social status and SP as risk factors are prone to an underestimation of effects because hospitalization is more frequent in lower social classes [30].

Galobardes [31] pointed out that childhood social status has an influence on later health outcomes. This may be mediated through school education that determines later employment opportunities via different pathways [32, 33]. This study did not include information on parental social class. Parental SES influence childhood socioeconomic prospects including social and economic resources particularly education which affects adult SES [34]. However, occupational status may be considered as a factor with an effect that lasts continuously and having more influence on health outcomes than education.

Educational and occupational opportunities may differ by economic system and over time. No differences were found when data from the two study centres of former socialist states Croatia and Czech Republic were analysed separately (data not shown). In addition, there was no difference observed by leaving French subjects (recruitment period: 1987-1992) from analysis. Different willingness to be interviewed can be a possible element of bias for SP. In view of a $68 \%$ participation rate in this study such an effect may be small.

The strength of this study is the measure SP on the basis of full detailed life history of occupations. This information was obtained by in-person interviews; no surrogate interviews were taken. In addition, the study participants were not aware of the SP analysis. Performed tasks and occupations are reported accurately even if the interviewer is aware of the case-control status [35].

SIOPS can be measured exactly through the occupational title and allows a much more differentiated ranking of job titles than the traditional classification into manual and nonmanual workers. A further advantage is its unambiguous hierarchical order. Differences can be expressed in terms of exact numerical values, but periods of unemployment and illness cannot be ranked by this scale. Non-consideration of such periods may lead to an underestimation of any SP differences [36].

The strongest negative association between SP and tumour risk was observed for tumours of the oesophagus, while for tumours of the hypopharynx and larynx the associations were weak. The strongest risk was observed for transition from high to low SP while reduced risk was 
Table 3 Distributions and risk estimates with $95 \%$-confidence intervals of transition in SP for first occupation to occupation with maximum value achieved at any time, first occupation to social status prestige at last occupation and for maximum value occupation to last occupation for cases and controls
${ }^{\text {a }}$ Reference. $\mathrm{OR}_{1}$, adjusted for age and study centre; $\mathrm{OR}_{2}$, adjusted for age; study centre, smoking status, cumulative tobacco consumption, alcohol drinking status, alcohol drinking frequency, fruit and vegetable intake frequency

* Categories chosen for an equal frequency of occupations within scaling points $L=$ $14-33, M=34-45, H=46-78$

\begin{tabular}{|c|c|c|c|c|}
\hline \multirow[t]{2}{*}{ Transition in SP* } & Cases & Controls & \multirow[t]{2}{*}{$\mathrm{OR}_{1}[95 \%-\mathrm{CI}]$} & \multirow[t]{2}{*}{$\mathrm{OR}_{2}[95 \%-\mathrm{CI}]$} \\
\hline & $\%$ & $N$ & & \\
\hline
\end{tabular}

First occupation to occupation with maximum prestige

$\begin{array}{lrrrrll}H \rightarrow H & 215 & 11.97 & 267 & 16.85 & 1^{\mathrm{a}} & 1^{\mathrm{a}} \\ H \rightarrow M & 31 & 1.73 & 25 & 1.58 & 1.53[0.87-2.67] & 1.11[0.60-2.05] \\ H \rightarrow L & 20 & 1.11 & 12 & 0.76 & 2.00[0.95-4.19] & 1.71[0.75-3.87] \\ M \rightarrow H & 175 & 9.74 & 230 & 14.51 & 1.01[0.77-1.32] & 1.01[0.75-1.37] \\ M \rightarrow M & 496 & 27.62 & 374 & 23.60 & 1.70[1.36-2.13] & 1.26[0.98-1.62] \\ M \rightarrow L & 120 & 6.68 & 91 & 5.74 & 1.68[1.21-2.33] & 1.08[0.75-1.54] \\ L \rightarrow H & 105 & 5.85 & 134 & 8.45 & 1.01[0.74-1.39] & 0.76[0.54-1.08] \\ L \rightarrow M & 222 & 12.36 & 184 & 11.61 & 1.56[1.19-2.04] & 0.98[0.73-1.32] \\ L \rightarrow L & 412 & 22.94 & 268 & 16.91 & 1.93[1.52-2.33] & 1.24[0.95-1.61]\end{array}$

Change of SP from first occupation to last occupation

\begin{tabular}{lrrrrll}
$H \rightarrow H$ & 194 & 10.80 & 256 & 16.15 & $1^{\mathrm{a}}$ & $1^{\mathrm{a}}$ \\
$H \rightarrow M$ & 37 & 2.06 & 26 & 1.64 & $1.89[1.10-3.22]$ & $1.51[0.84-2.72]$ \\
$H \rightarrow L$ & 35 & 1.95 & 22 & 1.39 & $2.12[1.20-3.73]$ & $1.58[0.85-2.94]$ \\
$M \rightarrow H$ & 125 & 6.96 & 192 & 12.11 & $0.93[0.69-1.24]$ & $0.97[0.70-1.34]$ \\
$M \rightarrow M$ & 425 & 23.66 & 330 & 20.82 & $1.76[1.39-2.23]$ & $1.33[1.02-1.73]$ \\
$M \rightarrow L$ & 241 & 13.42 & 173 & 10.91 & $1.95[1.48-2.56]$ & $1.28[0.95-1.73]$ \\
$L \rightarrow H$ & 80 & 4.45 & 96 & 6.06 & $1.14[0.80-1.63]$ & $0.88[0.60-1.30]$ \\
$L \rightarrow M$ & 142 & 7.91 & 128 & 8.08 & $1.52[1.12-2.06]$ & $0.91[0.64-1.27]$ \\
$L \rightarrow L$ & 517 & 28.79 & 362 & 22.84 & $1.94[1.54-2.45]$ & $1.24[0.96-1.62]$ \\
\hline
\end{tabular}

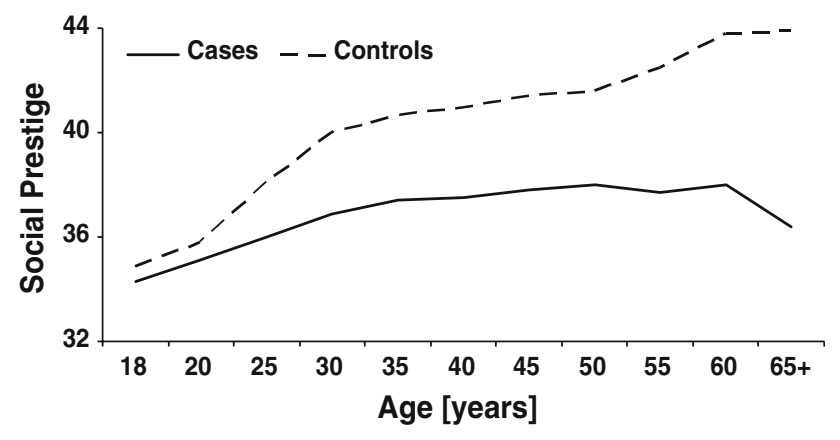

Fig. 2 Development of mean value of social prestige for cases and controls according to age. Number of cases from 18 to $65+$ were $1,318,1,444,1,688,1,746,1,741,1,702,1,585,1,337,971,518,183$, and number of controls 1,078, 1,224, 1,453, 1,533, 1,531, 1,496, $1,400,1,209,907,520,212$

observed for low to high transitions, although this was based on a small number of observations.

Pre-diagnostic health problems of cases could influence the most recent SP transition by reducing the chance to change into higher positions and increasing the chance for downward transitions. However, this is not a plausible explanation of the results since only occupations with a duration of at least 3 years were solicited in the ARCAGEquestionnaire and an increased risk for maximum SP at age
21-30 to age 51-60, i.e. long before the disease was diagnosed was also observed.

Alcohol abuse may have an independent and direct effect on transitions of SP. Different studies show consequences of high alcohol consumption and binge drinking, including economic loss due to time off work because of alcoholrelated illness or injury, unemployment, disruption of family and social relationships, emotional problems and impact on perceived health [37-42]. Patterns of alcohol consumption differ by social class, e.g. members of higher social classes tend to drink more frequently, while members of lower classes tend to drink more heavily [40, 41, 43].

Smoking and alcohol behaviours seem to explain most of the risks associated with socioeconomic mobility [44]. However, the main finding in this study is the association between downward transitions of SP and UADT tumours which is attenuated but not eliminated after adjustment for alcohol and tobacco consumption and fruit and vegetable intake frequency. Despite different methods used to assess social inequality, the findings of our study are consistent with previous studies $[11,15,27,45,46]$. A particular causal mechanism by which SP acts on the development of UADT cancers remains to be elucidated. The complexities of occupational circumstances and how they interact with other causal factors associated with social status is not entirely clear and can not be disentangled completely in such an analysis. 
Table 4 Distributions and risk estimates within $95 \%$ confidence intervals for maximal social prestige achieved in 10-year intervals of age for cases and controls
${ }^{\text {a }}$ Reference. $\mathrm{OR}_{1}$ : adjusted for age and study centre, $\mathrm{OR}_{2}$ : adjusted for age, study centre, smoking status, cumulative tobacco consumption, alcohol drinking status, alcohol drinking frequency, fruit and vegetable intake frequency. Total indicates the number of 1,796 cases and 1,585 controls which were economically active for at least 1 year within the specific 10 -year interval and considered for analyses

* Categories chosen for an equal frequency of occupations within scaling points $L=$ $14-33, M=34-45, H=46-78$

\begin{tabular}{|c|c|c|c|c|c|c|}
\hline \multirow[t]{2}{*}{ SP category* } & \multicolumn{2}{|l|}{ Cases } & \multicolumn{2}{|c|}{ Controls } & \multirow[t]{2}{*}{$\mathrm{OR}_{1}[95 \%-\mathrm{CI}]$} & \multirow[t]{2}{*}{$\mathrm{OR}_{2}[95 \%-\mathrm{CI}]$} \\
\hline & $N$ & $\%$ & $N$ & $\%$ & & \\
\hline \multicolumn{7}{|l|}{ Age $21-30$} \\
\hline$H$ & 399 & 22.43 & 489 & 31.29 & $1^{\mathrm{a}}$ & $1^{\mathrm{a}}$ \\
\hline$M$ & 825 & 46.37 & 688 & 44.02 & 1.49 [1.26-1.76] & $1.13[0.94-1.36]$ \\
\hline$L$ & 555 & 31.20 & 386 & 24.70 & $1.75[1.46-2.11]$ & 1.18 [0.96-1.45] \\
\hline Total & 1,779 & & 1,563 & & & \\
\hline \multicolumn{7}{|l|}{ Age $31-40$} \\
\hline$H$ & 418 & 23.55 & 551 & 35.16 & $1^{\mathrm{a}}$ & $1^{\mathrm{a}}$ \\
\hline$M$ & 712 & 40.11 & 570 & 36.38 & 1.64 [1.39-1.95] & $1.26[1.04-1.52]$ \\
\hline$L$ & 645 & 36.34 & 446 & 28.46 & $1.90[1.60-2.27]$ & $1.32[1.09-1.61]$ \\
\hline Total & 1,775 & & 1,567 & & & \\
\hline \multicolumn{7}{|l|}{ Age $41-50$} \\
\hline$H$ & 428 & 25.07 & 543 & 36.30 & $1^{\mathrm{a}}$ & $1^{\mathrm{a}}$ \\
\hline$M$ & 626 & 36.67 & 508 & 33.36 & 1.57 [1.32-1.86] & $1.16[0.96-1.41]$ \\
\hline$L$ & 653 & 38.25 & 445 & 29.75 & $1.85[1.55-2.21]$ & $1.24[1.01-1.50]$ \\
\hline Total & 1,707 & & 1,496 & & & \\
\hline \multicolumn{7}{|l|}{ Age $51-60$} \\
\hline$H$ & 331 & 26.12 & 428 & 37.19 & $1^{\mathrm{a}}$ & $1^{\mathrm{a}}$ \\
\hline$M$ & 427 & 33.70 & 383 & 33.28 & 1.41 [1.16-1.72] & 1.11 [0.89-1.39] \\
\hline$L$ & 509 & 40.17 & 340 & 29.54 & $1.90[1.55-2.32]$ & 1.28 [1.02-1.60] \\
\hline Total & 1,267 & & 1,151 & & & \\
\hline \multicolumn{7}{|l|}{ Age $>60$} \\
\hline$H$ & 93 & 25.91 & 189 & 48.09 & $1^{\mathrm{a}}$ & $1^{\mathrm{a}}$ \\
\hline$M$ & 97 & 27.02 & 100 & 25.45 & 1.95 [1.34-2.85] & $1.43[0.95-2.16]$ \\
\hline$L$ & 169 & 47.08 & 104 & 26.46 & 3.39 [2.37-4.86] & $2.62[1.78-3.86]$ \\
\hline Total & 359 & & 393 & & & \\
\hline
\end{tabular}

The pathway from social factors to biological change in the aetiology of cancer is not entirely clear, but emerging hypotheses include the 'biological ageing' effects resulting from pour socioeconomic circumstances [47]. The biological ageing hypothesis basically proposes that poor people age faster due to the social and physical environments to which they are exposed, such that poor people die younger, but from the same conditions as their richer counterparts. There may also be a genetic role within this socioeconomic_biological ageing-cancer aetiological pathway, perhaps mediated by shortened telomeres [47-50].

However, research of the psychosocial mechanisms through which inequality may act, focuses on investigating the biologically plausible pathways between inequalities through loss of social capital and the resulting psychophysiological stresses it brings. Neuroendocrine responses, including the chronic secretion of stress-response hormones, and in particular the inability to cope or recover from this, may have an impact on the immune system, especially in relation to the cardiovascular system [51]. Most of the evidence on this is related to cardiovascular disease and less regarding cancer aetiology. However, it is possible to see a potential link in that the immune system, and a chronic inflammation in particular, have been implicated in the aetiology of cancer [52].

A further potential strand to the psychosocial explanation comes from the work by Everson et al. (1996). In their Finish longitudinal study they found men with high selfrated feelings of "hopelessness", which correlated with low socioeconomic status, were at increased cardiovascular and cancer risk. This suggests a possible association with mental health conditions.

The psychosocial mechanisms may help elucidate the physiological pathway leading from downward socioeconomic mobility to UADT cancer risk observed over and above the behavioural risk factors. Specifically, these results may have some parallels in the research of psychosocial effects of work stress although as yet there is only empirical evidence in relation to coronary heart disease, musculoskeletal disorders, and mental illness [51]. The lower intake of fruit and vegetables observed among cases compared to controls might be a further hint for a psychosocial impact, since persons with low awareness or with low family connectedness are found to consume less often fruit and vegetables [53-55]. 
Acknowledgments We would like to thank all the patients and their families for their participation. We are also grateful to the support of many clinicians and staff of the hospitals, interviewers, data managers, pathology departments, and primary care clinics. GJM and TVM partly worked on this study while at the University of Manchester. They acknowledge the help of Dr A-M Biggs, Dr R Oliver and Professor M Tickle in study conduct in the Manchester centre and Professor P Sloan and Professor N Thakker who in addition coordinated sample collection and processing for all the UK centres. Funding was received from European Community (5th Framework Programme) grant no. QLK1-CT-2001-00182.

\section{References}

1. Tarvainen L, Kyyronen P, Kauppinen T, Pukkala E. Cancer of the mouth and pharynx, occupation and exposure to chemical agents in Finland [in 1971-95]. Int J Cancer. 2008;123:653-9.

2. Ferlay J, Autier P, Boniol M, Heanue M, Colombet M, Boyle P. Estimates of the cancer incidence and mortality in Europe in 2006. Ann Oncol. 2007;18:581-92.

3. Baron AE, Franceschi S, Barra S, Talamini R, La VC. A comparison of the joint effects of alcohol and smoking on the risk of cancer across sites in the upper aerodigestive tract. Cancer Epidemiol Biomarkers Prev. 1993;2:519-23.

4. Freedman ND, Park Y, Subar AF, Hollenbeck AR, Leitzmann MF, Schatzkin A, et al. Fruit and vegetable intake and head and neck cancer risk in a large United States prospective cohort study. Int J Cancer. 2008;122:2330-6.

5. Sapkota A, Hsu CC, Zaridze D, Shangina O, Szeszenia-Dabrowska N, Mates D, et al. Dietary risk factors for squamous cell carcinoma of the upper aerodigestive tract in central and eastern Europe. Cancer Causes Control. 2008;19(10):1161-70.

6. Boeing H, Dietrich T, Hoffmann K, Pischon T, Ferrari P, Lahmann $\mathrm{PH}$, et al. Intake of fruits and vegetables and risk of cancer of the upper aero-digestive tract: the prospective EPIC-study. Cancer Causes Control. 2006;17:957-69.

7. Boffetta P, Kogevinas M, Simonato L, Wilbourn J, Saracci R. Current perspectives on occupational cancer risks. Int J Occup Environ Health. 1995;1:315-25.

8. Makela P, Valkonen T, Martelin T. Contribution of deaths related to alcohol use of socioeconomic variation in mortality: register based follow up study. BMJ. 1997;315:211-6.

9. Makela P. Alcohol-related mortality as a function of socio-economic status. Addiction. 1999;94:867-86.

10. Hemstrom O. Alcohol-related deaths contribute to socioeconomic differentials in mortality in Sweden. Eur J Public Health. 2002; 12:254-62.

11. Bosetti C, Franceschi S, Negri E, Talamini R, Tomei F, La VC. Changing socioeconomic correlates for cancers of the upper digestive tract. Ann Oncol. 2001;12:327-30.

12. Conway DI, Petticrew M, Marlborough H, Berthiller J, Hashibe M, Macpherson LM. Socioeconomic inequalities and oral cancer risk: a systematic review and meta-analysis of case-control studies. Int J Cancer. 2008;122:2811-9.

13. Conway DI, McKinney PA, McMahon AD, Ahrens W, Schmeisser N, Benhamou S, Bouchardy C, Macfarlane GJ, Macfarlane TV, Lagiou P, Minaki P, Bencko V, Holcatova I, Merletti F, Richiardi L, Kjaerheim K, Agudo A, Castellsague X, Talamini R, Barzan L, Canova C, Simonato L, Lowry RJ, Znaor A, Healy CM, McCartan BE, Marron M, Hashibe M, Brennan P. Socioeconomic factors associated with risk of upper aerodigestive tract cancer in Europe. Eur J Cancer. 2009. doi:10.1016/j.ejca.2009. 09.028
14. Jansson C, Johansson AL, Nyren O, Lagergren J. Socioeconomic factors and risk of esophageal adenocarcinoma: a nationwide Swedish case-control study. Cancer Epidemiol Biomarkers Prev. 2005;14:1754-61.

15. Menvielle G, Luce D, Goldberg P, Leclerc A. Smoking, alcohol drinking, occupational exposures and social inequalities in hypopharyngeal and laryngeal cancer. Int J Epidemiol. 2004;33:799806.

16. Nagel G, Linseisen J, Boshuizen HC, Pera G, Del GG, Westert GP, et al. Socioeconomic position and the risk of gastric and oesophageal cancer in the European Prospective Investigation into Cancer and Nutrition (EPIC-EURGAST). Int J Epidemiol. 2007;36:66-76.

17. Treiman D. Occupational prestige in comparitive perspectivequantitative studies in social relations. New York: Academic Press; 1977.

18. Wolf C. Sozioökonomischer Status und berufliches Prestige. Ein kleines Kompendium sozialwissenschaftlicher Skalen auf der Basis der beruflichen Stellung und Tätigkeit. ZUMA-Nachrichten. 1995;37(19):102-36.

19. Lantz PM, House JS, Lepkowski JM, Williams DR, Mero RP, Chen J. Socioeconomic factors, health behaviors, and mortality: results from a nationally representative prospective study of US adults. JAMA. 1998;279:1703-8.

20. Schrijvers CT, Stronks K, van de Mheen HD, Mackenbach JP. Explaining educational differences in mortality: the role of behavioral and material factors. Am J Public Health. 1999; 89:535-40.

21. Shavers VL. Measurement of socioeconomic status in health disparities research. J Natl Med Assoc. 2007;99:1013-23.

22. Conway DI, McMahon AD, Smith K, Taylor JC, McKinney PA. Socioeconomic factors influence selection and participation in a population-based case-control study of head and neck cancer in Scotland. J Clin Epidemiol. 2008;61:1187-93.

23. Lagiou P, Georgila C, Minaki P, Ahrens W, Pohlabeln H, Benhamou $\mathrm{S}$, et al. Alcohol-related cancers and genetic susceptibility in Europe: the ARCAGE project: study samples and data collection. Eur J Cancer Prev. 2009;18:76-84.

24. International Labour Office. International standard classification of occupations. ISCO68. Revised ed. Geneva: International Labour Office; 1968.

25. Lagiou P, Talamini R, Samoli E, Lagiou A, Ahrens W, Pohlabeln $\mathrm{H}$, et al. Diet and upper-aerodigestive tract cancer in Europe: the ARCAGE study. Int J Cancer. 2009;124:2671-6.

26. Altieri A, Bosetti C, Gallus S, Franceschi S, Dal ML, Talamini R, et al. Wine, beer and spirits and risk of oral and pharyngeal cancer: a case-control study from Italy and Switzerland. Oral Oncol. 2004;40:904-9.

27. Ferraroni M, Negri E, La VC, D’Avanzo B, Franceschi S. Socioeconomic indicators, tobacco and alcohol in the aetiology of digestive tract neoplasms. Int J Epidemiol. 1989;18:556-62.

28. Morse DE, Psoter WJ, Cleveland D, Cohen D, Mohit-Tabatabai M, Kosis DL, et al. Smoking and drinking in relation to oral cancer and oral epithelial dysplasia. Cancer Causes Control. 2007;18:919-29.

29. Schlecht NF, Franco EL, Pintos J, Negassa A, Kowalski LP, Oliveira $\mathrm{BV}$, et al. Interaction between tobacco and alcohol consumption and the risk of cancers of the upper aero-digestive tract in Brazil. Am J Epidemiol. 1999;150:1129-37.

30. Saxena S, George J, Barber J, Fitzpatrick J, Majeed A. Association of population and practice factors with potentially avoidable admission rates for chronic diseases in London: cross sectional analysis. J R Soc Med. 2006;99:81-9.

31. Galobardes B, Lynch JW, Smith GD. Is the association between childhood socioeconomic circumstances and cause-specific 
mortality established? Update of a systematic review. J Epidemiol Commun Health. 2008;62:387-90.

32. Pekkanen J, Tuomilehto J, Uutela A, Vartiainen E, Nissinen A. Social class, health behaviour, and mortality among men and women in eastern Finland. BMJ. 1995;311:589-93.

33. Winkleby MA, Fortmann SP, Rockhill B. Trends in cardiovascular disease risk factors by educational level: the Stanford FiveCity Project. Prev Med. 1992;21:592-601.

34. Davey SG, Hart C, Hole D, MacKinnon P, Gillis C, Watt G, et al. Education and occupational social class: which is the more important indicator of mortality risk? J Epidemiol Commun Health. 1998;52:153-60.

35. Ahrens W, Jockel KH, Patzak W, Elsner G. Alcohol, smoking, and occupational factors in cancer of the larynx: a case-control study. Am J Ind Med. 1991;20:477-93.

36. Martikainen P, Valkonen T. Bias related to the exclusion of the economically inactive in studies on social class differences in mortality. Int J Epidemiol. 1999;28:899-904.

37. Bobak M, Room R, Pikhart H, Kubinova R, Malyutina S, Pajak A, et al. Contribution of drinking patterns to differences in rates of alcohol related problems between three urban populations. J Epidemiol Commun Health. 2004;58:238-42.

38. Casswell S, Pledger M, Hooper R. Socioeconomic status and drinking patterns in young adults. Addiction. 2003;98:601-10.

39. Viner RM, Taylor B. Adult outcomes of binge drinking in adolescence: findings from a UK national birth cohort. J Epidemiol Commun Health. 2007;61:902-7.

40. Hemmingsson T, Lundberg I, Diderichsen F, Allebeck P. Explanations of social class differences in alcoholism among young men. Soc Sci Med. 1998;47:1399-405.

41. Hemmingsson T, Lundberg I, Diderichsen F. The roles of social class of origin, achieved social class and intergenerational social mobility in explaining social-class inequalities in alcoholism among young men. Soc Sci Med. 1999;49:1051-9.

42. Rehm J, Gmel G. Patterns of alcohol consumption and social consequences. Results from an 8-year follow-up study in Switzerland. Addiction. 1999;94:899-912.

43. Smith GW, Shevlin M. Patterns of alcohol consumption and related behaviour in Great Britain: a latent class analysis of the alcohol use disorder identification test (AUDIT). Alcohol Alcohol. 2008;43:590-4.
44. Gruer L, Hart CL, Gordon DS, Watt GC. Effect of tobacco smoking on survival of men and women by social position: a 28 year cohort study. BMJ. 2009;338:b480.

45. La VC, Negri E, Franceschi S. Education and cancer risk. Cancer. 1992;70:2935-41.

46. Marshall B, Chevalier A, Garillon C, Goldberg M, Coing F. Socioeconomic status, social mobility and cancer occurrence during working life: a case-control study among French electricity and gas workers. Cancer Causes Control. 1999;10:495502 .

47. Adams JM, White M. Biological ageing: a fundamental, biological link between socio-economic status and health? Eur J Public Health. 2004;14:331-4.

48. Epel ES, Blackburn EH, Lin J, Dhabhar FS, Adler NE, Morrow JD, et al. Accelerated telomere shortening in response to life stress. Proc Natl Acad Sci U S A. 2004;101:17312-5.

49. Cherkas LF, Aviv A, Valdes AM, Hunkin JL, Gardner JP, Surdulescu GL, et al. The effects of social status on biological aging as measured by white-blood-cell telomere length. Aging Cell. 2006;5:361-5.

50. Cawthon RM, Smith KR, O'Brien E, Sivatchenko A, Kerber RA. Association between telomere length in blood and mortality in people aged 60 years or older. Lancet. 2003;361:393-5.

51. Marmot M, Siegrist J, Theorell T. Health and the psychosocial environment at work. In: Marmot M, Wilkinson WR, editors. Social determinants of health. Oxford: Oxford University Press; 2006. p. 97-130.

52. O'Byrne KJ, Dalgleish AG. Chronic immune activation and inflammation as the cause of malignancy. $\mathrm{Br} \mathrm{J}$ Cancer. 2001;85:473-83.

53. Bachner-Melman R, Zohar AH, Elizur Y, Kremer I, Golan M, Ebstein R. Protective self-presentation style: association with disordered eating and anorexia nervosa mediated by sociocultural attitudes towards appearance. Eat Weight Disord. 2009;14:1-12.

54. Neumark-Sztainer D, Story M, Resnick MD, Blum RW. Correlates of inadequate fruit and vegetable consumption among adolescents. Prev Med. 1996;25:497-505.

55. Riediger ND, Shooshtari S, Moghadasian MH. The influence of sociodemographic factors on patterns of fruit and vegetable consumption in Canadian adolescents. J Am Diet Assoc. 2007;107:1511-8. 